\title{
INTERPRETASI IMAM AL-MARAGHI DAN IBNU KATSIR TERHADAP QS. ALI IMRAN AYAT 190-191
}

Wida Nafila Sofia

UIN Sunan Gunung Djati Bandung

Email: sofiawidanafila@gmail.com

\begin{tabular}{l}
\hline Keywords: \\
Interpretation of \\
Imam Al-Maraghi, \\
Interpretation of \\
Ibnu Katsir, Ali \\
Imran Verse 190- \\
191.
\end{tabular}

\section{Keywords:}

Interpretation of Interpretation of Ibnu Katsir, Ali 191.

\begin{abstract}
This paper is stimulated by the fact that education is an activity that is deliberately carried out to actualize all the potential of students, both in the affective, cognitive and psychomotor domains, both soul (nafs), heart (qalb) and intellectual ('aql). The reality that has happened is that the education system has only been able to produce weak people, with the characteristics of low initiative and creativity, low self-confidence, helplessness and ultimately unable to be independent. In the Al-Qur'an, there are many verses that call on people to pay attention to, reflect on and compose Allah, whether in the heavens, the earth or among. Among the verses that explain this are Q.S Ali Imran verses 190-191. Data obtained through literature studies from several books and journals that explain Al-Maraghi and Ibn Kathir's interpretation of QS. Ali Imran 190-191 as the focus of discussion. This research reveals that as human beings we must always remember Allah SWT and also measure what Allah SWT has created so that we can take a response. This also requires the integration of the function of reason and dhikr as a unity that must be present in every Muslim, in order to be able to take lessons from the signs of the power of Allah SWT.
\end{abstract}

\begin{tabular}{l} 
Abstrak \\
\hline Artikel ini dibuat berdasarkan fakta bahwa pendidikan \\
merupakan aktivitas yang sengaja dilakukan untuk \\
mengaktualisasikan segala potensi peserta didik, baik ranah \\
afektif, kognitif maupun psikomotorik, baik jiwa (nafs), hati \\
(qalb) maupun intelektual ('aql). Realita yang terjadi sistem \\
pendidikan ternyata baru mampu menghasilkan orang-orang \\
lemah, dengan ciri rendah daya inisiatif dan kreativitas, \\
rendah rasa percaya diri, tidak berdaya dan pada ujungnya \\
tidak sanggup mandiri. Dalam Al-Qur'an banyak terdapat \\
ayat-ayat yang menyerukan manusia untuk memperhatikan, \\
merenung dan memikirkan penciptaan Allah baik yang di \\
langit, bumi maupun diantara keduanya. Diantara ayat-ayat \\
yang menerangkan tentang hal tersebut yaitu Q.S Ali Imran \\
ayat 190-191. Data diperoleh melalui studi literatur dari
\end{tabular}

http://pasca.jurnalikhac.ac.id/index.php/tijie/index 
beberapa buku dan jurnal yang menjelaskan interpretasi AlMaraghi dan Ibnu Katsir tentang QS. Ali Imran 190-191 sebagai fokus pembahasan. Penelitian ini mengungkapkan bahwa sebagai manusia kita harus senantiasa ingat kepada Allah SWT dan juga memikirkan apa yang telah Allah SWT ciptakan sehingga kita dapat mengambil suatu pelajaran darinya. Hal ini juga mengharuskan adanya integrasi antara fungsi akal yaitu berpikir dengan dzikir sebagai satu kesatuan yang harus ada pada setiap orang muslim, agar mampu mengambil hikmah-hikmah yang terdapat pada tanda-tanda kekuasaan Allah SWT.

\section{PENDAHULUAN}

Pendidikan merupakan aktivitas yang sengaja dilakukan untuk mengaktualisasikan segala potensi peserta didik, baik ranah afektif, kognitif maupun psikomotorik, baik jiwa (nafs), hati (qalb) maupun intelektual ('aql)1. Pendidikan merupakan usaha sadar untuk mengembangkan individu secara penuh dan memuat norma dan nilai-nilai yang menjadi penting dalam semua perencanaan pendidikan. Islam memberikan suatu norma objektif tersebut, yang bersumber dari Al-Qur'an dan hadits ${ }^{2}$.

Realita yang terjadi sistem pendidikan ternyata baru mampu menghasilkan orang-orang lemah, dengan ciri rendah daya inisiatif dan kreativitas, rendah rasa percaya diri, tidak berdaya dan pada ujungnya tidak sanggup mandiri. Orang lemah selalu ingin mencari yang kuat untuk menggantungkan hidupnya. Sistem pendidikan yang tidak dialogis juga telah menyebabkan bakat dan kreativitas peserta didik tidak mampu berkembang secara baik. Hal ini menunjukkan suatu kegagalan pendidikan dalam menghasilkan output berkualitas. Kegagalan lain yang menimpa dunia

${ }^{1}$ Afiful Ikhwan, "Leadership in Islamic Education: Study of Thematic Al-Qur'an and AlHadist," ULUL ALBAB Jurnal Studi Islam 17, no. 1 (May 25, 2016): 31-46, https://doi.org/10.18860/ua.v17i1.3253; Baharuddin and Aziz Safa, Psikologi pendidikan: refleksi teoritis terhadap fenomena (Yogyakarta: Ar-Ruzz Media, 2007); Baharuddin, Paradigma Psikologi Islami, Studi tentang Elemen Psikologi dari Al-Qur`an, 2nd ed. (Yogyakarta: Pustaka Pelajar, 2007).

${ }^{2}$ Muhammad Anas Ma'arif, "Analisis Konsep Kompetensi Kepribadian Guru PAI Menurut AzZarnuji," ISTAWA 2, no. 2 (2017): 35-60, http://journal.umpo.ac.id/index.php/istawa/article/view/624; Muhammad Amin Abdullah, "Islamic Studies in Higher Education in Indonesia: Challenges, Impact and Prospects for the World Community," Al-Jami'ah: Journal of Islamic Studies 55, no. 2 (December 15, 2017): 391-426, https://doi.org/10.14421/ajis.2017.552.391-426; Zareena A. Grewal and R. David Coolidge, "Islamic Education in the United States:: Debates, Practices, and Institutions," in The Cambridge Companion to American Islam, ed. Juliane Hammer and Omid Safi, Cambridge Companions to Religion (Cambridge: Cambridge University Press, 2013), 246-65, https://doi.org/10.1017/CCO9781139026161.017.

Vol.2, No.1, January 2021

Tafkir: Interdisciplinary Journal of Islamic Education 
pendidikan saat ini adalah persoalan inkosistensi, irasionalitas, pragmatisme, suka mencari jalan pintas dan serba instant.

Hal itu merupakan persoalan budaya dan mentalitas yang ditimbulkan oleh kesalahan dalam mendidik, yaitu cendrung menindas peserta didik. Hal ini menyebabkan produk pendidikan selama ini sering melakukan manipulasi, korupsi dan menindas sesama 3 . Pada masa perkembangan, lembaga pendidikan ternyata tidak menjadi media pembebasan dan penanaman nilai-nilai kemanusiaan. Sekolah menjadi "penjara" yang memisahkan peserta didik dari dinamika persoalan masyarakatnya. Semakin lama orang bersekolah, semakin besar jarak antara dirinya dengan realitas kehidupan yang sebenarnya, sehingga, menghasilkan output yang tidak bertanggungjawab dan tidak berbudaya (not civilizid) ${ }^{4}$.

Manusia adalah makhluk Allah SWT yang paling mulia dibandingkan dengan makhluk lainnya. Karena Allah telah mengutamakannya dengan memberikannya akal untuk berfikir. Kemudian dengan berfikir ia akan memperoleh ilmu yang akan membawanya kepada ketaqwaan terhadap Allah SWT. Sebagaimana yang dikatakan oleh Azzarnuji dalam kitabnya ta'lim al-mutaallim "Sesungguhnya Islam Berjaya dengan Ilmu dan tiadalah seseorang akan sampai kepada kezuhudan dan ketakwaan kepada Allah SWT kecuali dengan ilmu.5" Di dalam Al-Qur'an orang-orang yang menggunakan akalnya diberi sebutan dengan gelar ulul albab (orang-orang yang berfikir dan berdzikir) yang harus dijadikan contoh atau tauladan di dalam dunia akademis, karena ia adalah manusia yang berilmu, yang dengan ilmunya itu ia mampu mengarahkan akalnya, serta ia juga mampu mengetahui dirinya yaitu sebagai makhluk yang harus melakukan pengabdian kepada Allah SWT yang telah menciptakannya 6 .

${ }^{3}$ Andika Aprilianto and Muhammad Arif, "Pendidikan Islam Dan Tantangan Multikultural: Tinjauan Filosofis," Nazhruna: Jurnal Pendidikan Islam 2, no. 2 (August 11, 2019): 279-89, https://doi.org/10.31538/nzh.v2i2.339; Shalahudin Ismail et al., "The Competence of Millennial Islamic Education Teachers in Facing The Challenges of Industrial Revolution," Nazhruna: Jurnal Pendidikan Islam 3, no. 3 (November 4, 2020): 389-405, https://doi.org/10.31538/nzh.v3i3.823.

4 Ali Mustofa, "ULUL ALBAB PERSPEKTIF PENDIDIKAN ISLAM DALAM QS.ALI IMRAN: 190-191 DAN QS. AL-ZUMAR: 9," Jurnal Urwatul Wutsqo 5, no. 1 (2016): 73.

${ }_{5}$ Burhanul Islam Al-Zarnuji, Ta`limul Muta`alim (Surabaya: Al-Hidayah, n.d.); Alfianoor Rahman, "Pendidikan Akhlak Menurut Az-Zarnuji Dalam Kitab Ta'lim al-Muta'allim," At-Ta'dib 11, no. 1 (June 1, 2016), https://doi.org/10.21111/at-tadib.v11i1.647.

6 Arizqi Ihsan Pratama, "KONSEP ULIL ALBAB DALAM AL-QURAN DAN RELEVANSINYA TERHADAP PENDIDIKAN MODERN," ACIEDSS 1, no. 2 (2019): 222-23.

Vol.2, No.1, January 2021

Tafkir: Interdisciplinary Journal of Islamic Education 
Sebagai pedoman hidup bagi umat manusia, pembicaraan Al-Qur'an terhadap satu masalah sangat unik, tidak tersusun seperti sistematika buku-buku ilmu pengetahuan yang dikarang manusia. Di samping itu, Al-Qur'an juga sangat jarang menyajikan suatu masalah secara rinci dan detail7. Pembicaraan Al-Qur'an terhadap suatu masalah umumnya bersifat global, parsial dan seringkali menampilkan masalah dalam substansinya saja. Keadaan demikian sama sekali tidak mengurangi nilai AlQur'an, sebaliknya justru di sanalah letak keunikan sekaligus keistimewaannya. Dengan keadaan seperti itu Al-Qur'an menjadi objek kajian yang tidak pernah kering oleh para cendekiawan, baik muslim maupun non muslim, sehingga ia tetap aktual dan mampu untuk selalu didialogkan dengan setiap situasi dan kondisi yang dilewatinya. Agar Al-Qur'an benar-benar bisa menjadi pedoman bagi manusia, diperlukan pemahaman yang benar atas ayat-ayat Al-Qur'an. Terlebih lagi apabila penafsiran terhadap Al-Qur'an dilakukan oleh ahlinya maka hasil penafsirannya sangat berguna sebagai refrensi hidup umat Islam ${ }^{\text {. }}$

Kata yang paling tepat untuk dirujuk dalam konteks makna dan tugas cendekiawan muslim dewasa ini adalah ulul albab, karena dalam kata ulul albab itu terdapat kombinasi antara ulama dan pemikir yang terlihat jelas. Kata ulul albab merupakan sebuah konsep yang penting dalam al-Qur'an karena berkaitan dengan hakikat sosial keberagaman Islam. Kata ulul albab disebut dalam Al-Qur'an sebanyak enam belas kali. Ulul albab ini yang nantinya diharapkan mampu menjadi sebuah tawaran output pendidikan, mengingat kegagalan-kegagalan pendidikan yang telah disebutkan di atas.

Dalam Al-Qur'an banyak terdapat ayat-ayat yang menyerukan manusia untuk memperhatikan, merenung dan memikirkan penciptaan Allah baik yang di langit, bumi maupun diantara keduanya. Diantara ayat-ayat yang menerangkan tentang hal tersebut yaitu Q.S Ali Imran ayat 190-191. Kedua ayat ini masuk dalam kelompok penutup surat Ali Imran. Dalam ayat ini Allah SWT menguraikan sekelumit dari penciptaan-Nya itu serta memerintahkan agar memikirkannya. Sesuai dengan tujuan

${ }^{7}$ Nazilatus Syukriyah, "Membumikan Al-Quran Dalam Etika Santri Kepada Kyai; Studi Tafsir Q.S Al Kahfi Ayat 66 - 70," Nazhruna: Jurnal Pendidikan Islam 2, no. 2 (August 11, 2019): 209-24, https://doi.org/10.31538/nzh.v2i2.269.

${ }^{8}$ M. Khoirul Hadi, "KARAKTERISTIK TAFSIR AL-MARĀGHĪ DAN PENAFSIRANNYA TENTANG AKAL,” HUNAFA: Jurnal Studia Islamika 11, no. 1 (2014): 155-156.

Vol.2, No.1, January 2021

Tafkir: Interdisciplinary Journal of Islamic Education 
utama surat Ali Imran diturunkan adalah untuk membuktikan tentang tauhid, keesaan dan kekuasaan Allah SWT. Hakikat ini kembali ditegaskan pada ayat ini dan ayat yang akan datang. Salah satu dari bukti kebenaran hal tersebut adalah mengundang manusia untuk berpikir, karena sesungguhnya dalam penciptaan, yakni kejadian benda-benda angkasa seperti matahari, bulan dan jutaan gugusan bintang yang terdapat di langit atau dalam pengaturan sistem kerja langit yang sangat teliti serta kejadian dan perputaran bumi pada porosnya yang melahirkan silih bergantinya malam dan siang, perbedaannya baik dalam masa, maupun dalam panjang dan pendeknya terdapat tanda-tanda kemahakuasaan Allah SWT bagi ulul Albab yakni orang-orang yang memiliki akal yang murni ${ }^{9}$

Dalam konteks pengembangan ilmu pendidikan khususnya, Al-Qur'an merupakan salah satu sumber rujukan. Tafsir pendidikan sebagai upaya eksplorasi dan interpretasi ayat-ayat yang berhubungan dengan pendidikan dan menjadi kajian yang menarik untuk terus dikembangkan. Penarikan makna dari ayat Al-Qur'an yang diteliti berhubungan dengan pendidikan membutuhkan sebuah piranti yang valid dan sistematis. Salah satu hal penting yang harus dipahami pada proses penafsiran ayat yang berhubungan dengan pendidikan adalah munasbah al Ayat wa al surah (korelasi ayat dan surat) ${ }^{10}$. Begitupula dalam penelitian ini yang akan membahas tentang interpretasi dari Al-Maraghi dan Ibnu Katsir tentang QS. Ali Imran 190-191.

\section{METODE PENELITIAN}

Subjek penelitian ini adalah beberapa buku dan jurnal yang menjelaskan tentang Tafsir Al-Maraghi dan Ibnu Katsir tentang QS. Ali Imran 190-191 sebagai fokus pembahasan. Data dikumpulkan melalui studi pustaka dan dianalisis menggunakan teknik analisis data kualitatif.

\section{HASIL PENELITIAN DAN PEMBAHASAN}

\section{Makna Ulul Albab dalam Al-Qur'an}

Menurut Mufassir, Ulul Albab adalah istilah khusus yang dipakai Al-Qur'an untuk menyebutkan sekelompok manusia pilihan semacam intelektual. Istilah itu disebutkan sebanyak 16 kali dalam Al-Qur'an. Namun sejauh itu Al-Qur'an sendiri tidak menjelaskan secara definitif konsepnya tentang Ulul Albab. Ia hanya

${ }^{9}$ M. Quraish Shihab, Tafsir Al-Misbah (Jakarta: Lentera Hati, 2005).

${ }^{10}$ Rudi Ahmad Suryadi, "SIGNIFIKANSI MUNASABAH AYAT AL-QURAN DALAM TAFSIR PENDIDIKAN," Jurnal Studi Islam 17, no. 1 (2016): 72.

Vol.2, No.1, January 2021

Tafkir: Interdisciplinary Journal of Islamic Education 
menyebutkan tanda-tandanya saja. Karena itulah para mufassir kemudian memberikan pengertian yang berbeda-beda tentang Ulul Albabi11.

Ulul albab berasal dari dua suku kata, yakni uluu atau ulii yang bermakna yang memiliki, dan al-albab sebagai bentuk jamak dari kata $l u b b$ yang bermakna bagian penting dari sesuatu. Definisi ulul albab dalam Al-Qur'an diterjemahkan berbeda oleh beberapa cendekiawan, yakni orang yang berakal sebagaimana diartikan oleh Yunus, Hamka mengartikan ulul albâb sebagai orang yang mempunyai pikiran, Hamidi mengartikan ulul albâb sebagai orang yang mengerti, sementara Rifa'i mengartikannya sebagai orang yang berakal kuat, dan Abdullah Yusuf Ali mengartikannya sebagai Men of Understanding ${ }^{12}$.

Terdapat dua unsur penting dalam ulul albab yaitu berfikir dan berdzikir. Berfikir dan berdzikir ini merupakan satu kesatuan yang berdiri sendiri namun keduanya tidak bisa dipisahkan karena keduanya saling berhubungan. Maksudnya ketika kita berdzikir kita tidak akan terlepas dari berfikir pun ketuka kita berfikir maka kita harus berdampingan dengan berdzikir kepada Allah. Berdzikir merupakan kegiatan menuntut ilmu yang bersungguh-sungguh, dikatakan demikian sebab dalam berdzikir kita akan sungguh-sungguh berfikir. Berfikir tentang ke-Esa-an Allah SWT tentang bagaimana Allah yang Maha Baik memberikan kita segala kemampuan sehingga menjadi manusia yang istimewa ${ }^{13}$.

\section{Lafal dan Terjemahan QS. Ali Imran Ayat 190-191}

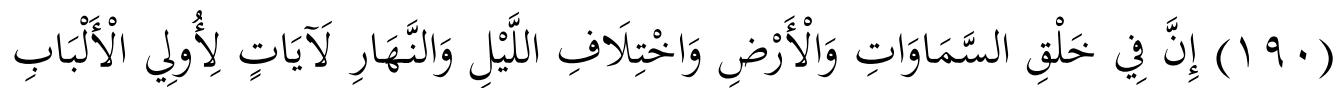

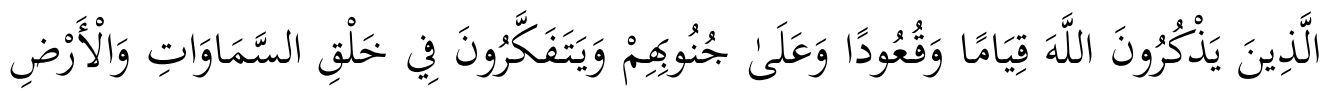

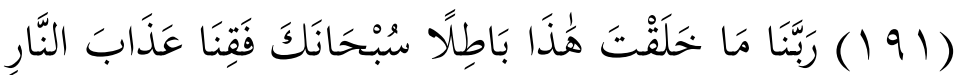

"Sesungguhnya dalam penciptaan langit dan bumi, dan silih bergantinya malam dan siang terdapat tanda-tanda bagi orang-orang yang berakal. (Yaitu) orang-orang yang mengingat

${ }^{11}$ Sri Aliyah, "ULUL ALBAB DALAM TAFSIR FI ZHILALI AL-QURAN," Jurnal JIA 14, no. 1 (2013): 119.

12 Waway Qodratulloh S., “KONSEP ULUL ALBAB DALAM AL-QUR'AN DAN IMPLIKASINYA DALAM PEMBELAJARAN PENDIDIKAN AGAMA ISLAM DI PERGURUAN TINGGI," Jurnal Sigma-Mu 8, no. 1 (2016): 19.

${ }^{13}$ Dea Marti Fauziyyah, Dedih Surana, and A.M Rasyid, "Konsep Ulul Albab Dalam AlQuran Surat Ali-Imran Ayat 190-191 Serta Implikasinya Terhadap Pendidikan Islam," Prosiding Pendidikan Agama Islam 5, no. 2 (2019): 386.

Vol.2, No.1, January 2021

Tafkir: Interdisciplinary Journal of Islamic Education 
Allah sambil berdiri atau duduk atau dalam keadan berbaring dan mereka memikirkan tentang penciptaan langit dan bumi (seraya berkata): "Ya Tuhan Kami, Tiadalah Engkau menciptakan ini dengan sia-sia, Maha suci Engkau, Maka peliharalah Kami dari siksa neraka."14

\section{Asbabun Nuzul QS. Ali Imran Ayat 190-191}

Menurut Az-Zarqani mendefinisikan asbab an-nuzul sebagai berikut:

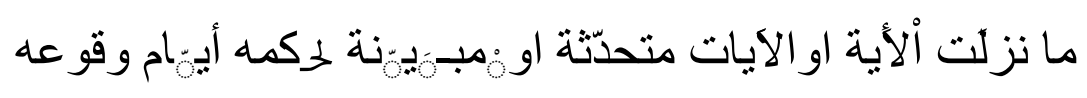

"Peristiwa yang menjadi sebab turunnya suatu ayat atau beberapa ayat, dimana ayat tersebut bercerita atau menjelaskan tentang suatu hukum mengenai peristiwa tersebut pada waktu terjadinya."

Dari pengertian di atas terlihat adanya sebab yaitu peristiwa yang terjadi pada Nabi SAW yang melatar belakangi turunnya ayat atau adanya pertanyaan yang ditujukan kepada Nabi SAW dimana pertanyaan itu menjadi menjadi sebab turunnya suatu ayat sebagai jawaban dari pertanyaan tersebut. Jadi apabila dilihat dari sisi asbabun nuzulnya, ayat Al-Qur'an diklasifikasikan menjadi dua kelompok, pertama ayat-ayat yang mempunyai sebab turunnya ayat dan yang kedua adalah ayat-ayat turun tidak didahului oleh suatu peristiwa atau pertanyaan. Jadi dalam al Qur'an ada ayat yang mempunyai asbabun nuzul dan ada ayat yang tidak mempunyai asbabun nuzul15.

Adapun asbabun nuzul Q.S. Ali ‘Imran ayat 190-191 adalah :

Ath-Thabrani dan Ibnu Abi Hatim meriwayatkan dari Ibnu Abbas, dia berkata, “orang-orang Quraisy mendatangi orang-orang Yahudi dan bertanya kepada mereka, apa tanda-tanda yang dibawa Musa kepada kalian?" orang-orang Yahudi itu menjawab "Tongkat dan tangan yang putih bagi orang-orang yang melihatnya." Lalu orang-orang Quraisy itu mendatangi orang-orang Nasrani, lalu bertanya kepada mereka, “apa tanda-tanda yang diperlihatkan Isa?.” Mereka menjawab, “Dia dulu menyembuhkan orang yang buta, orang yang sakit kusta dan menghidupkan orang mati." Lalu mereka mendatangi Nabi SAW. lalu berkata kepada beliau, "Berdoalah kepada Tuhanmu untuk mengubah bukit shafa menjadi emas untuk kami." Lalu beliau berdoa, maka turunlah firman Allah (Q.S Ali Imran 190-191) ini16.

\footnotetext{
${ }^{14}$ Departemen Agama RI, Al-Qur'an Dan Tafsirnya Jilid II (Jakarta: Lentera Abadi, 2010).

${ }^{15}$ M. Yusuf Kadar, Studi Al-Qur'an (Jakarta: Amzah, 2009).

${ }^{16}$ Jalaluddin As-Suyuthi, Asbabun Nuzul: Sebab-Sebab Turunnya Ayat Al-Qur'an, Terj. Lubaabun Nuquul Fii Asbaabin Nuzuul, Tim Abdul Hayyie (Jakarta: Gema Insani, 2008).
} 
Pada peristiwa asbabun nuzul tersebut, terlihat bahwa pada saat itu kaum Quraisy belum dapat menghayati dan mensyukuri akan nikmat yang telah diberikan Allah SWT kepada mereka, dimana mereka tidak mau memikirkan akan hikmah dari penciptaan alam semesta beserta segala isinya. Padahal jika mereka mau memikirkan hal tersebut, mereka akan mendapatkan banyak pelajaran, manfaat dan faedah. Hamparan alam semesta ini diciptakan penuh dengan makna, pada setiap sisi terdapat tanda-tanda yang menunjukkan akan kekuasaan Allah SWT.

\section{Munasabah Al-Qur'an Surat Ali Imran Ayat 190-191}

Kata munasabah secara etimologis berasal dari kata nasaba yang bersinonim dengan al-Qarabah yang berarti dekat. Kata munasabah secara harfiah mempunyai arti al-Muqarabah (kedekatan) dan al-Musyakalah (kemiripan). Sedangkan, ilmu munasabah merupakan suatu ilmu yang mempelajari hubungan antara satu ayat dengan ayat lain atau antara satu surat dengan surat lain sebagaimana urutannya telah tersusun dalam Al-Qurean ${ }^{17}$.

Kelompok ayat ini merupakan penutup surat Ali Imran. Ayat ini memiliki keterkaitan dengan ayat sebelumnya, yakni ayat 189:

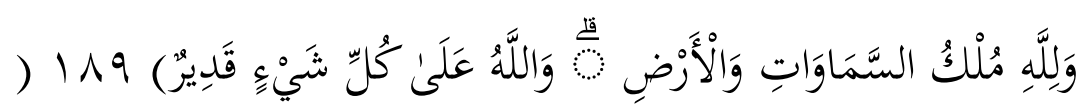

"Kepunyaan Allah-lah kerajaan langit dan bumi, dan Allah Maha Perkasa atas segala sesuatu."

Ayat yang lalu menyebutkan keburukan-keburukan orang Yahudi, dan menegaskan bahwa langit dan bumi milik Allah, maka dalam ayat-ayat ini Allah menganjurkan untuk mengenal sifat-sifat keagungan, kemuliaan dan kebesaran Allah. Ayat ini menegaskan kepemilikan Allah SWT atas alam raya,apa yang ada di langit dan di bumi adalah kepunyaan Allah. Allah Maha Kaya, Maha Perkasa atas segala sesuatu.

Pada ayat 190-191 Allah menguraikan sekelumit dari penciptaan-Nya serta memerintahkan agar memikirkannya. Apalagi seperti dikemukakan pada awal uraian surat ini bahwa tujuan surat Ali Imran adalah membuktikan tentang tauhid, keesaan, dan kekuasaan Allah SWT. Hukum-hukum alam yang melahirkan kebiasaan-

17 Abdullah Mawardi, Ulumul Qur'an (Yogyakarta: Pustaka Pelajar, 2011).

Vol.2, No.1, January 2021

Tafkir: Interdisciplinary Journal of Islamic Education 
kebiasaan, pada hakikatnya ditetapkan dan diatur oleh Allah Yang Maha Hidup lagi Qayyum (Maha Menguasai dan Maha Mengelola segala sesuatu).

Selain dengan ayat sebelumnya, Surat Ali Imran ayat 190-191 juga memiliki keterkaitan dengan ayat setelahnya yaitu 192-194:

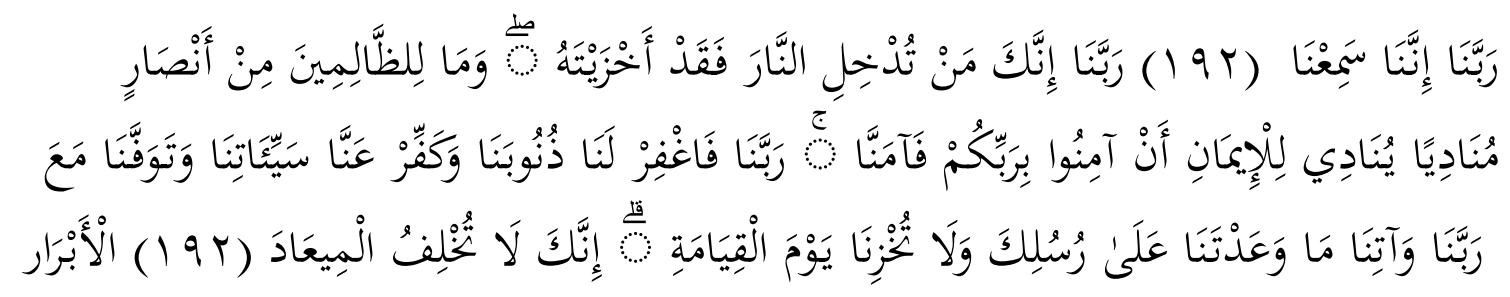

"Ya Tuhan Kami, Sesungguhnya Barangsiapa yang Engkau masukkan ke dalam neraka, Maka sungguh telah Engkau hinakan ia, dan tidak ada bagi orang-orang yang zalim seorang penolongpun.Ya Tuhan Kami, Sesungguhnya Kami mendengar (seruan) yang menyeru kepada iman, (yaitu): "Berimanlah kamu kepada Tuhanmu", Maka Kamipun beriman. Ya Tuhan Kami, ampunilah bagi Kami dosa-dosa Kami dan hapuskanlah dari Kami kesalahan-kesalahan Kami, dan wafatkanlah Kami beserta orang-orang yang banyak berbakti.Ya Tuhan Kami, berilah Kami apa yang telah Engkau janjikan kepada Kami dengan perantaraan Rasul-rasul Engkau. dan janganlah Engkau hinakan Kami di hari kiamat. Sesungguhnya Engkau tidak menyalahi janji."

Dalam ayat tersebut dijelaskan mengenai pengakuan atas kebesaran Allah, mereka yang mengerti dan paham ajaran agama memohon agar dihindarkan dari siksa neraka.Doa saja belum cukup untuk dapat terhindar dari siksa neraka sebab kedurhakaan, melainkan dengan ketulusan dan dibarengi usaha sadar terus menerus untuk menjadi makhluk yang baik dan taat terhadap perintah Allah SWT. Mereka berdoa agar diwafatkan dalam keadaan berkakti supaya dapat mendiami surga bersama orang-orang yang berbakti. Mereka memohon ampunan agar tidak dihina dan dipermalukan di hari kiamat atas dosanya yang telah diperbuat sebelumnya. Allah tidak pernah dan tidak akan mengingkari janji, dalam arti meereka menyadari bahwa kalau permohonan mereka tidak diterima Allah, maka bukan karena Allah mengingkari janji, tetapi karena merekalah tidak memenuhi syarat perolehan janji itu ${ }^{18}$.

\section{Interpretasi Al-Maraghi terhadap QS. Ali Imran Ayat 190-191}

Interpretasi dalam Kamus Besar Bahasa Indonesia (KBBI) diartikan sebagai pemberian kesan, pendapat, tafsiran, atau pandangan teoritis terhadap sesuatu. Istilah

${ }_{18}$ M. Quraish Shihab, Al-Lubab: Makna, Tujuan Dan Pelajaran Dari Surah-Surah Al-Qur'an (Tangerang: Lentera Hati, 2012). 
interpretasi bisa merujuk pada proses penafsiran yang sedang berlangsung atau hasil dari proses tersebut. Suatu interpretasi bisa menjadi bagian dari presentasi atau penggambaran informasi yang diubah, dengan tujuan menyesuaikan kumpulan simbol spesifik.

Pada dasarnya, dalam tradisi keilmuan dikatan bahwa seorang mufassir di dalam menafsirkan sebuah teks tidak akan pernah terlepas dari sejarah hidupnya, latarbelakang intelektualnya, keilmuan yang dimilikinya, pemikiran guru-guru serta keadaan masyarakat ketika ia hidup ${ }^{19}$.

Begitu juga dengan Al-Maraghi. Nama lengkap Ahmad Al-Mustafa ibn Muhammad ibn 'Abd al-Mun' in al-Qadi al-Maraghi, ia lahir pada tahun $1300 \mathrm{H} / 1883$ M di kota al-Maraghah, provinsi suhaj, kira-kira 700 meter dari arah selatan kota Kairo. Ahmad Mustafa al-Maraghi berasal dari keluarga ulama yang taat dan menguasai berbagai ilmu agama, hal ini dapat dibuktikan bahwa 5 dari 8 orang putra laki-laki Syekh Mustafa al-Maraghi (ayah Ahmad Musstafa Al-Maraghi) adalah ulama besar yang cukup terkenal ${ }^{20}$.

Berikut Tasfir Al-Maraghi tentang Qs. Ali-Imran ayat 190-191:

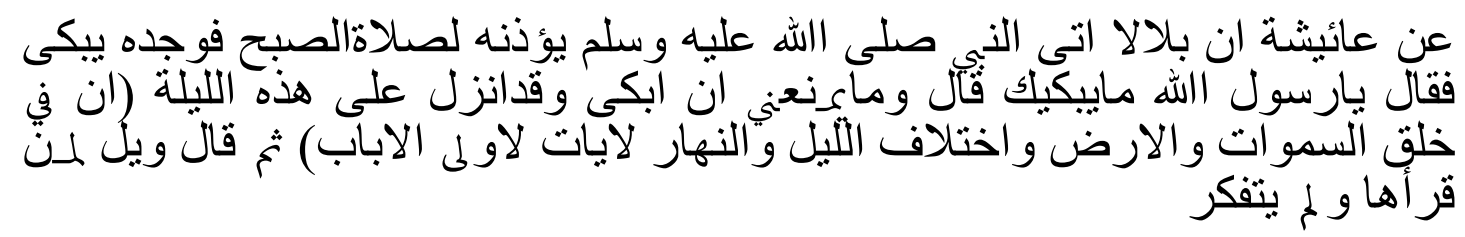

"Dari Sayyidah Aisyah Radhiyallahu 'Anha, "Sesungguhnya sahabat Bilal datang kepada Nabi SAW. Sahabat Bilal akan mengumandangkan azan untuk shalat subuh kemudian sahabat Bilal mendapati Nabi SAW. sedang menangis maka Bilal berkata: Ya Rasulallah, apa yang menyebabkan engkau menangis, Nabi menjawab: "tidak ada sesuatu yang dapat mencegahku menangis dan seseungguhnya telah turun pada malam ini ayat ("Sesungguhnya dalam penciptaan langit dan bumi, dan silih bergantinya malam dan siang terdapat tanda-tanda bagi orang-orang yang berakal). Kemudian Nabi SAW. Bersabda: "Celakalah bagi orang yang membacanya dan tidak memikirkannya."

Ulūl-albāb adalah orang-orang yang mau menggunakan pikirannya, mengambil faedah darinya, mengambil hidayah darinya, menggambarkan keagungan Allah dan

19 Arifin Hidayat, “METODE PENAFSIRAN AL-QUR'AN MENGGUNAKAN PENDEKATAN LINGUISTIK (Telaah Pemikiran M. Syahrur)," Jurnal Madaniyah 7, no. 2 (2017): 207.

20 M. Khoirul Hadi, "KARAKTERISTIK TAFSIR AL-MARĀGHĪ DAN PENAFSIRANNYA TENTANG AKAL," HUNAFA: Jurnal Studia Islamika 11, no. 1 (2014): 155156.

Vol.2, No.1, January 2021

Tafkir: Interdisciplinary Journal of Islamic Education 
mau mengingat hikmah akal dan keutamaannya, di samping keagungan karunia-Nya dalam segala sikap dan perbuatan mereka, sehingga mereka bisa berdiri, duduk, berjalan, berbaring dan sebagainya. Mereka tidak lalai untuk mengingat Allah dalam sebagian waktunya, merasa tenang dengan mengingat Allah dan tenggelam dalam kesibukan mengoreksi diri secara sadar bahwa Allah selalu mengawasi mereka.

Seorang mukmin yang mau menggunakan akal pikirannya, selalu menaruh pengharapan hanya kepada Allah melalui pujian, doa dan ibtihal, setelah melihat bukti-bukti keagungan Allah yang menunjukkan keindahan hikmah. Mereka tahu bagaimana berbicara dengan Tuhan ketika telah mendapatkan hidayah terhadap sesuatu terkait dengan kebajikan dan kedermawanan-Nya dalam menghadapi ragam makhluk-Nya.

Sesungguhnya dalam tatanan langit dan bumi serta keindahan perkiraan dan keajaiban ciptaan-Nya dalam silih bergantinya siang dan malam secara teratur sepanjang tahun yang dapat kita rasakan langsung pengaruhnya pada tubuh kita dan cara berpikir kita karena pengaruh panas matahari, dinginnya malam, dan pengaruhnya pada dunia flora dan fauna, dan sebagainya merupakan tanda dan bukti yang menunjukkan keesaan Allah, kesempurnaan pengetahuan dan kekuasaan-Nya.

Ahmad Mushthafa Al-Maraghi menyimpulkan, bahwa ulul albab adalah orangorang yang tidak melalaikan Allah SWT dalam sebagian waktunya. Mereka merasa tenang dengan mengingat Allah SWT dan tenggelam dalam kesibukan mengoreksi diri secara sadar bahwa Allah SWT selalu mengawasi mereka. Dan hanya dengan melakukan zikir kepada Allah SWT, hal itu masih belum cukup untuk menjamin hadirnya hidayah. Tetapi harus pula dibarengi dengan memikirkan keindahan ciptaan dan rahasia-rahasia ciptaan-Nya ${ }^{21}$.

\section{Interpretasi Ibnu Katsir terhadap QS. Ali Imran Ayat 190-191}

Dalam kajian ilmu Al-Qur'an dan tafsir, nama Ibnu Katsir sama sekali tidak asing. Nama aslinya adalah Isma'il bin Umar bin Katsir bin Dhau bin Katsir bin Dhau bin Zar', Al-Qaisi, Al-Quraisyi, Al-Busrawi, Ad-Dimasyqi, Asy-Syafi'i. Menurut Ibnu Hajar al-Asqalani, ia lahir pada tahun 700 H/ 1301 M. Ia merupakan salah satu murid Ibnu Taimiyah dan dimakamkan disamping makam gurunya tersebut pada $774 \mathrm{H} /$

${ }^{21}$ Ahmad Mustafa Al-Maraghi, Tafsir Al-Maragi, Juz IV, Terj. Tafsir Al-Maraghi, Bahrun Abu Bakar Dkk (Semarang: Karya Toha Putra, 1993).

Vol.2, No.1, January 2021 
1372 M. Dia tinggal di Damaskus dan belajar kepada banyak ulama disana. Ibnu Katsrir juga pernah belajar di Mesir dan diakui kealimannya oleh para Ulama sezamannya maupun sesudahnya ${ }^{22}$.

Menurut Ibnu Katsir, pada Qs. Al-Imran ayat yang ke-190-191 Allah menguraikan sekelumit dari penciptaan-Nya, serta memerintahkan agar memikirkannya. Salah satu bukti kebenaran bahwa Allah merupakan Sang Pemilik atas alam raya ini, dengan adanya undangan kepada manusia untuk berpikir, karena sesungguhnya dalam penciptaan, yakni kejadian benda-benda angkasa, seperti matahari, bulan dan jutaan gugusan bintang-bintang yang terdapat dilangit, atau dalam pengaturan sistem kerja langit yang sangat teliti serta kejadian dan perputaran bumi pada porosnya yang melahirkan silih bergantinya malam dan siang, perbedaannya baik dalam masa maupun panjang dan pendeknya terdapat tanda-tanda kemahakuasaan Allah bagi ulul albab, yakni orang orang yang memiliki akal yang murni.

Kata (الباب) al-bab adalah bentuk jamak dari (لب) lub yaitu "saripati" sesuatu. Kacang misalnya, memiliki kulit yang menutupi isinya. Isi kacang dinamai lub. Ulul albab adalah orang-orang yang memiliki akal yang murni, yang tidak diselubungi oleh "kulit", yakni kabut ide yang dapat melahirkan kerancuan dalam berpikir. Orang yang merenungkan tentang penomena alam raya akan dapat sampai kepada bukti yang sangat nyata tentang keesaan dan kekuasaan Allah Swt.

Ibnu Katsir menyatakan bahwa yang disebut ulul albab adalah Yaitu akal yang sempurna dan bersih yang dengannya dapat diketemukan berbagai keistimewaan dan keagungan mengenai sesuatu bukan seperti orang-orang yang buta dan bisu yang tidak dapat berpikir.

\section{Ayat 190}

Makna pada ayat ini yaitu pada ketinggian dan keluasan langit dan juga pada kerendahan bumi serta kepadatannya. Dan juga tanda-tanda kekuasaan-Nya yang terdapat pada ciptaan-Nya yang dapat dijangkau oleh indera manusia pada keduanya (langit dan bumi) baik berupa bintang-bintang, komet, daratan dan lautan,

22 Saifuddin Zuhri Qudsy and Mamat S. Burhanuddin, "PENGGUNAAN HADIS-HADIS POLIGAMI DALAM TAFSIR IBNU KATSIR," Musãwa Jurnal Studi Gender dan Islam 15, no. 2 (July 17, 2016): 184.

Vol.2, No.1, January 2021

Tafkir: Interdisciplinary Journal of Islamic Education 
pegunungan dan lain sebagainya serta berbagai macam warna dan beragam makanan dan bebauan. Kemudian dengan hal itu, dibalutlah dengan silih bergantinya, susul menyusulnya, panjang dan pendeknya malam dan siang. Semua itu merupakan ketetapan Allāh SWT yang Maha Pengatur lagi Maha Menguasai segala sesuatu. Oleh karena itu diakhir ayat Allāh SWT berfirman "Terdapat tanda-tanda bagi orang-orang yang berakal (Ūlul Albāb). Yaitu mereka yang mempunyai akal sempurna lagi bersih, yang mengetahui hakikat banyak hal secara jelas dan nyata.

\section{Ayat 191}

Dalam ayat ini Allāh SWT menyifati tentang Ūlul Albāb : "(Yaitu) orang-orang yang mengingat Allāh sambil berdiri, duduk atau dalam keadaan berbaring." Sebagaimana hadits yang disebutkan oleh Rasūlullāh SAW.

Maksudnya adalah mereka tidak putus-putus berdzikir dalam semua keadaan, baik dengan hati maupun dengan lisan. Mereka juga memahami apa yang terdapat diantara keduanya (langit dan bumi) dari kandungan hikmah yang menunjukkan keagungan Allāh SWT, kekuasaan-Nya, keluasan ilmu-Nya, hikmah-Nya, pilihanNya juga rahmat-Nya.

Allāh SWT memuji hamba-hamba-Nya yang beriman "(Yaitu) orang- orang yang mengingat Allāh sambil berdiri, duduk atau dalam keadaan berbaring dan mereka memikirkan tentang penciptaan langit dan bumi."

Yang mana mereka berkata, "Ya Tuhan kami, tidaklah Engkau menciptakan ini dengan sia-sia." Artinya, Engkau (Allāh SWT) tidak menciptakan semuanya ini dengan sia-sia, tetapi dengan penuh kebenaran, agar Engkau memberikan balasan kepada orang-orang yang beramal. Kemudian mereka (Ūlul Albāb) menyucikan Allāh SWT dari perbuatan sia-sia dan penciptaan yang bathil dengan menyebut "Maha Suci Engkau. Lalu meminta perlindungan dari adzab Allāh SWT dengan menyebutkan "Maka lindungilah kami dari siksa Neraka." Maksudnya, wahai Rabb yang menciptakan makhluk ini dengan sungguh-sungguh dan adil. Wahai Dzat yang jauh dari kekurangan, aib dan kesia-siaan, lindungilah kami dari adzab Neraka. Dan berikanlah 
taufik kepada kami dalam menjalankan amal shalih yang dapat mengantarkan kami ke Syurga serta menyelamatkan kami dari adzab-Mu yang sangat pedih23.

\section{Aspek Pendidikan dalam QS. Ali Imran Ayat 190-191}

Dari QS. Ali Imran ayat 190-191 dapat diambil aspek tarbawinya yaitu sebagai berikut24: Akal manusia hendaknya digunakan untuk memikirkan, menganalisa, dan menafsirkan segala ciptaan Allah. Dalam belajar tidak diperbolehkan memikirkan Dzat Allah, karena manusia mempunyai keterbatasan dalam hal tersebut dan dikhawatirkan akan terjerumus dalam berpikir yang tidak sesuai. Hendaknya manusia mempercayai bahwa semua penciptaan Allah tidak ada yang sia-sia.

Atas penciptaan alam semesta ini, hendaknya kita menyadari tugas sebagai khalifah Allah, yang berkewajiban memakmurkan bumi serta menjadi rahmat bagi alam sekelilingnya, dengan menggali, meneliti dan memanfaatkan hukum-hukum Allah bagi alam ciptaan-Nya ini, sebagai bentuk dari profil manusia ulul albab.

Akal manusia berdiri atas berbagai dimensi manusia, dimensi luar yang disebut 'aql/qalb, dimensi dalam yang disebut lubb, yang dapat menangkap dan menggali makna tersembunyi dibalik sesuatuyang konkrit, berakal sempurna. Tingkat akal paling sempurna yakni fu'ad yang menunjuk kepada pengertian 'nurani' yang berasal dari Allah. Hati nurani yang suci yang mendapat bimbingan lansung dari Allah. Ketiga fitrah potensi tadi akan memancarkan nur Ilahiyah keseluruh tubuh. Kepada lidah melahirkan bacaan zikir. Ke sel-sel syaraf akan melahirkan pikiran dan pemikiran yang benar. Dari pikiran dan pemikiran yang benar secara harmonis akan membentuk gerak dan prilaku yang juga benar.

\section{KESIMPULAN}

Dalam Al-Qur'an banyak terdapat ayat-ayat yang menyerukan manusia untuk memperhatikan, merenung dan memikirkan penciptaan Allah baik yang di langit, bumi maupun diantara keduanya. Diantara ayat-ayat yang menerangkan tentang hal tersebut yaitu Q.S Ali Imran ayat 190-191. Dalam ayat ini Allah SWT menguraikan sekelumit dari penciptaan-Nya itu serta memerintahkan agar memikirkannya. Sesuai

${ }^{23}$ Abdullah bin Muhammad bin Abdurrahman bin Ishaq Al-Sheikh, Lubaabut Tafsiir Min Ibnu Katsiir (Tafsir Ibnu Katsir) Juz 4, Penj. Tim Abdul Ghoffar (Bogor: Pustaka Imam Asy-Syafi'i, 2003). 2015).

${ }^{24}$ M. Daud Yahya, Nilai-Nilai Pendidikan Dalam Al-Qur'an (Banjarmasin: Antasari Press, 
dengan tujuan utama surat Ali Imran diturunkan adalah untuk membuktikan tentang tauhid, keesaan dan kekuasaan Allah SWT. Hakikat ini kembali ditegaskan pada ayat ini dan ayat yang akan datang.

Al-Maraghi menginterpretasikan QS. Ali Imran ayat 190-191, sesungguhnya dalam tatanan langit dan bumi serta keindahan perkiraan dan keajaiban ciptaan-Nya dalam silih bergantinya siang dan malam secara teratur sepanjang tahun yang dapat kita rasakan langsung pengaruhnya pada tubuh kita dan cara berpikir kita karena pengaruh panas matahari, dinginnya malam, dan pengaruhnya pada dunia flora dan fauna, dan sebagainya merupakan tanda dan bukti yang menunjukkan keesaan Allah, kesempurnaan pengetahuan dan kekuasaan-Nya.

Sedangkan Ibnu Katsir menginterpretasikan Qs. Al-Imran ayat yang ke 190-191, Allah menguraikan sekelumit dari penciptaan-Nya, serta memerintahkan agar memikirkannya. Salah satu bukti kebenaran bahwa Allah merupakan Sang Pemilik atas alam raya ini, dengan adanya undangan kepada manusia untuk berpikir, karena sesungguhnya dalam penciptaan, yakni kejadian benda-benda angkasa, seperti matahari, bulan dan jutaan gugusan bintang-bintang yang terdapat dilangit, atau dalam pengaturan sistem kerja langit yang sangat teliti serta kejadian dan perputaran bumi pada porosnya yang melahirkan silih bergantinya malam dan siang, perbedaannya baik dalam masa maupun panjang dan pendeknya terdapat tanda-tanda kemahakuasaan Allah bagi ulul albab, yakni orang orang yang memiliki akal yang murni.

Dari beberapa pendapat di atas tampak jelas bahwa QS. Ali Imran ayat 190-191 memerintahkan kita untuk senantiasa ingat kepada Allah SWT dan juga mau memikirkan apa yang telah Allah SWT ciptakan sehingga kita dapat mengambil suatu pelajaran darinya. Hal ini juga mengharuskan adanya integrasi antara fungsi akal yaitu berpikir dengan dzikir sebagai satu kesatuan yang harus ada pada setiap orang muslim, agar mampu mengambil hikmah-hikmah yang terdapat pada tanda-tanda kekuasaan Allah SWT. 


\section{REFERENSI}

Abdullah, Muhammad Amin. "Islamic Studies in Higher Education in Indonesia: Challenges, Impact and Prospects for the World Community." Al-Jami'ah: Journal of Islamic Studies 55, no. 2 (December 15, 2017): 391-426. https:// doi.org/10.14421/ajis.2017.552.391-426.

Aliyah, Sri. “ULUL ALBAB DALAM TAFSIR FI ZHILALI AL-QURAN.” Jurnal JIA 14, no. 1 (2013): 18.

Al-Maraghi, Ahmad Mustafa. Tafsir Al-Maragi, Juz IV, Terj. Tafsir Al-Maraghi, Bahrun Abu Bakar Dkk. Semarang: Karya Toha Putra, 1993.

Al-Sheikh, Abdullah bin Muhammad bin Abdurrahman bin Ishaq. Lubaabut Tafsiir Min Ibnu Katsiir (Tafsir Ibnu Katsir) Juz 4, Penj. Tim Abdul Ghoffar. Bogor: Pustaka Imam Asy-Syafi'i, 2003.

Al-Zarnuji, Burhanul Islam. Ta limul Muta`alim. Surabaya: Al-Hidayah, n.d.

Aprilianto, Andika, and Muhammad Arif. "Pendidikan Islam Dan Tantangan Multikultural: Tinjauan Filosofis." Nazhruna: Jurnal Pendidikan Islam 2, no. 2 (August 11, 2019): 279-89. https:// doi.org/10.31538/nzh.v2i2.339.

As-Suyuthi, Jalaluddin. Asbabun Nuzul: Sebab-Sebab Turunnya Ayat Al-Qur'an, Terj. Lubaabun Nuquul Fii Asbaabin Nuzuul, Tim Abdul Hayyie. Jakarta: Gema Insani, 2008.

Baharuddin. Paradigma Psikologi Islami, Studi tentang Elemen Psikologi dari Al-Qur`an. 2nd ed. Yogyakarta: Pustaka Pelajar, 2007.

Baharuddin, and Aziz Safa. Psikologi pendidikan: refleksi teoritis terhadap fenomena. Yogyakarta: Ar-Ruzz Media, 2007.

Fauziyyah, Dea Marti, Dedih Surana, and A.M Rasyid. "Konsep Ulul Albab Dalam AlQuran Surat Ali-Imran Ayat 190-191 Serta Implikasinya Terhadap Pendidikan Islam." Prosiding Pendidikan Agama Islam 5, no. 2 (2019).

Grewal, Zareena A., and R. David Coolidge. "Islamic Education in the United States:: Debates, Practices, and Institutions." In The Cambridge Companion to American Islam, edited by Juliane Hammer and Omid Safi, 246-65. Cambridge Companions to Religion. Cambridge: Cambridge University Press, 2013. https:// doi.org/10.1017/CCO9781139026161.017.

Hadi, M. Khoirul. "KARAKTERISTIK TAFSIR AL-MARĀGHĪ DAN PENAFSIRANNYA TENTANG AKAL." HUNAFA: Jurnal Studia Islamika 11, no. 1 (June 19, 2014): 153. https:/ / doi.org/10.24239/jsi.v11i1.345.153-172.

Hidayat, Arifin. "METODE PENAFSIRAN AL-QUR'AN MENGGUNAKAN PENDEKATAN LINGUISTIK (Telaah Pemikiran M. Syahrur)." Jurnal Madaniyah 7, no. 2 (2017): 18.

Ikhwan, Afiful. "Leadership in Islamic Education: Study of Thematic Al-Qur'an and Al-Hadist." ULUL ALBAB Jurnal Studi Islam 17, no. 1 (May 25, 2016): 31-46. https:// doi.org/10.18860/ua.v17i1.3253. 
Ismail, Shalahudin, Ma'mun Zahrudin, Uus Ruswandi, and Erihadiana Erihadiana.

"The Competence of Millennial Islamic Education Teachers in Facing The Challenges of Industrial Revolution." Nazhruna: Jurnal Pendidikan Islam 3, no. 3 (November 4, 2020): 389-405. https:// doi.org/10.31538/nzh.v3i3.823.

Kadar, M. Yusuf. Studi Al-Qur'an. Jakarta: Amzah, 2009.

Ma'arif, Muhammad Anas. "Analisis Konsep Kompetensi Kepribadian Guru PAI Menurut Az-Zarnuji." ISTAWA 2, no. 2 (2017): 35-60. http://journal.umpo.ac.id/index.php/istawa/article/view/624.

Mawardi, Abdullah. Ulumul Qur'an. Yogyakarta: Pustaka Pelajar, 2011.

Mustofa, Ali. "ULUL ALBAB PERSPEKTIF PENDIDIKAN ISLAM DALAM QS.ALI IMRAN: 190-191 DAN QS. AL-ZUMAR: 9." Jurnal Urwatul Wutsqo 5, no. 1 (2016): 20.

Pratama, Arizqi Ihsan. "KONSEP ULIL ALBAB DALAM AL-QURAN DAN RELEVANSINYA TERHADAP PENDIDIKAN MODERN." ACIEDSS 1, no. 2 (2019): 13.

Qodratulloh S., Waway. "KONSEP ULUL ALBAB DALAM AL-QUR'AN DAN IMPLIKASINYA DALAM PEMBELAJARAN PENDIDIKAN AGAMA ISLAM DI PERGURUAN TINGGI." Jurnal Sigma-Mu 8, no. 1 (2016).

Qudsy, Saifuddin Zuhri, and Mamat S. Burhanuddin. "PENGGUNAAN HADISHADIS POLIGAMI DALAM TAFSIR IBNU KATSIR." Musãwa Jurnal Studi Gender dan Islam 15, no. 2 (July 17, 2016): 181. https:// doi.org/10.14421/musawa.v15i2.1304.

Rahman, Alfianoor. "Pendidikan Akhlak Menurut Az-Zarnuji Dalam Kitab Ta'lim alMuta'allim." At-Ta'dib 11, no. 1 (June 1, 2016). https://doi.org/10.21111/attadib.v11i1.647.

RI, Departemen Agama. Al-Qur'an Dan Tafsirnya Jilid II. Jakarta: Lentera Abadi, 2010.

Shihab, M. Quraish. Al-Lubab: Makna, Tujuan Dan Pelajaran Dari Surah-Surah Al-Qur'an. Tangerang: Lentera Hati, 2012.

- - - . Tafsir Al-Misbah. Jakarta: Lentera Hati, 2005.

Suryadi, Rudi Ahmad. "SIGNIFIKANSI MUNASABAH AYAT AL-QURAN DALAM TAFSIR PENDIDIKAN." Jurnal Studi Islam 17, no. 1 (May 25, 2016): 71. https:// doi.org/10.18860/ua.v17i1.3331.

Syukriyah, Nazilatus. "Membumikan Al-Quran Dalam Etika Santri Kepada Kyai; Studi Tafsir Q.S Al Kahfi Ayat 66 - 70." Nazhruna: Jurnal Pendidikan Islam 2, no. 2 (August 11, 2019): 209-24. https:// doi.org/10.31538/nzh.v2i2.269.

Yahya, M. Daud. Nilai-Nilai Pendidikan Dalam Al-Qur'an. Banjarmasin: Antasari Press, 2015. 